get insight into front line, health care staff experiences with end-of-life issues. The study was undertaken in three distinct research sites in the Republic of Croatia and involved health care staff participants (physicians and nurses) from six health care institutions (six NICUs and six PICUs).

A total of 21 physicians and 25 nurses participated in eight focus groups.

Analysis revealed two main themes, that were equal among professional groups as well as NICU and PICU units. Theme critically ill child consisted of child, family, myself, and other professionals subthemes. Theme end-of-life procedures consisted of subthemes: breaking point, decision-making, end-oflife procedures, 'spill-over' and the four walls of the ICU.

Perceptions and experiences of end-of-life issues by nurses and physicians working in NICU and PICU share multiple common characteristics.

Interrelatedness of high emotional and cognitive demands and burden associated with end-of-life issues in this setting seems to have a significant influence on personal and professional lives of professionals.

Additionally, high variability of end-of-life applied procedures, and various difficulties experienced during shared decision-making process, stresses the need for developing guidelines that will inform such a practice, while considering specific perspectives of everyone involved.

\section{A REVIEW OF EXPERT RECOMMENDATIONS ON END- OF-LIFE ISSUES IN PEDIATRIC INTENSIVE CARE SETTING}

Sunčana Janković*, Marko Curković, Dina Vrkić, Ana Jozepović, Bojana Nevajdić, Milivoj Novak, Štefan Grosek, Ana Borovečki. UHC Zagreb

\subsection{6/archdischild-2021-europaediatrics.328}

One of the most ethically challenging issues in modern medicine are the ones related to end-of-life care. This is especially evident in intensive care setting where healthcare professionals are often involved in decisions about withholding or withdrawing potentially life-prolonging treatment and/or decisions on alleviation of suffering with a possible life-shortening effects. In pediatric intensive care setting, including both neonatal and pediatric intensive care units, there are additional layers of complexity added to end-of-life issues, as patients and their close ones are especially vulnerable and issues around usability, reliability and validity of surrogate decision makers are widespread. These complexities create many tensions that results with high variability on how end-of-life issues are approached in theoretical discussions, handled in practice. Not only that there is a high variability in that sense on global scale, but there is high variability within similar cultural, social, legal and health care contexts, as well as even between different institutions, units, and health care professionals in the single context. This creates a growing need for standardized, clinical and professional guidelines, ones that will be informed by all stakeholders that are included in this process.

There are many recommendations and guidelines regarding treatment end-of-life care crated by national and transnational institutions, while only few of them considering pediatric intensive care setting. In order to systematically identify them a systematic literature search in bibliographic databases and grey literature sources was conducted. The constant comparative qualitative analysis was used in order to identify and extricate their ethical content including ethical positions, ethical arguments and corresponding ethical principles. The aim was to extricate main ethical challenges, to explore how they are dealt with (on a theoretical and practical level), and to extricate main arguments and justifications on which their recommendations are based. The emphasis was placed on how those guidelines are handling specific end-of-life care issues regarding palliative care and/or palliative/terminal sedation; withholding and withdrawing of treatment interventions; and, where applicable, intentional terminating of life. Finally, similarities and disparities between these guidelines are presented and discussed, while also considering their (dis)similarities with guidelines dealing with end-of-life issues in adult intensive care settings.

*This article is part of the research 'Values and Decisions at the End of Life', funded by Croatian Science Foundation.

\section{DRUG INDUCED CARDIAC ARREST IN AN ADOLESCENT WITH HYPERTROPHIC CARDIOMYOPATHY?}

Toni Matić*, Ivan Bambir, Dalibor Šarić, Sanja Dorner, Miran Cvitković, Slobodan Galić, Filip Rubić, Sandro Dessardo, Milivoj Novak. Department of Paediatrics, University Hospital Centre Zagreb

10.1136/archdischild-2021-europaediatrics.329

We present an adolescent with newly diagnosed hypertrophic cardiomyopathy who suffered cardiac arrest with ventricular fibrillation.

We assume these conditions could have been caused by substances commonly abused by adolescents: anabolic steroids and synthetic cannabinoids Previously healthy, muscular, seventeen-year-old adolescent was examined by a paediatric cardiologist because of chest pain. Asymmetric hypertrophic cardiomyopathy without outflow tract obstruction was diagnosed, with sinus rhythm in 24 hour holter electrocardiogram. Avoidance of sport activities and bisoprolol therapy was suggested, which the patient did not comply to.

There were no heart diseases in the family history.

Four months after, the patient suddenly collapsed while sitting.

Resuscitation was started immediately and defibrillation was used because of ventricular fibrillation. Patient was transferred to the hospital. After additional 80 minutes of resuscitation with recurring ventricular fibrillation, a stable pulse was regained. Since the hemodynamic stability was not achieved with high catecholamine doses, venoarterial extracorporeal membrane oxygenation (ECMO) was administered, which stabilized the hemodynamic status. Day after, the ultrasound showed left ventricle ejection fraction of $45-50 \%$, and a thickened 26-milimeter septum with hyperechogenic and hypokinetic middle part, possibly attributed to ischemic necrosis. Four days later ECMO was discontinued. On day 32, the patient was discharged from the hospital in a good condition with a normal neurological status, and with implanted automatic cardioverter defibrillator.

Three months after the discharge, ultrasound showed a 15 milimeter septal thickness and left ventricle ejection fraction of $62 \%$. Cardioverter defibrillator was not activated after implantation. The patient's appearance was less muscular than at the time of incident.

Although we were not able to prove the presence of anabolic steroids, patient's muscular appearance and a newly 